\title{
Austenite transformation and age hardening of HSLA-80 and ULCB steels
}

\author{
Antonio Augusto Gorni ${ }^{\mathrm{a}, *}$, Paulo Roberto Mei ${ }^{\mathrm{b}}$ \\ ${ }^{a}$ Companhia Siderúrgica Paulista-COSIPA, Cubatão, SP, Brazil \\ ${ }^{\mathrm{b}}$ Universidade Estadual de Campinas-UNICAMP, Campinas, SP, Brazil
}

\begin{abstract}
Alternative materials to HY-80, quenched and tempered structural alloy steel, like the microalloyed steels HSLA-80 and ULCB, allow the suppression of the quenching and tempering heat treatment and offer better weldability due to their extra-low C content. In the HSLA-80 steel copper precipitation is one of the main hardening mechanisms available, while in the ULCB steel the contribution of the bainitic transformation plus solid solution hardening is vital. The aim of this work was to determine the continuous cooling austenite transformation (CCT) diagrams of both steels and its performance during age hardening. It was verified that both alloys developed a bainitic microstructure with low C content, commonly designed by the literature as "granular" bainite. The hardenability of the ULCB steel was greater than the HSLA- 80 due to the presence of Nb, B and Mo in the first alloy. The age hardening behavior of these alloys was slightly different between each other. The HSLA-80 steel developed maximum hardness during a $600{ }^{\circ} \mathrm{C}$ age hardening, while for the ULCB steel this occurred at a 500 or $600^{\circ} \mathrm{C}$ age hardening and took less time. Both steels showed a significant hardness decrease during the $700^{\circ} \mathrm{C}$ age hardening, that was probably due to overaging and tempering effects.
\end{abstract}

(C) 2004 Elsevier B.V. All rights reserved.

Keywords: HSLA-80 and ULCB steels; CCT diagram; Precipitation; Copper

\section{Introduction}

Quenched and tempered structural steels with medium alloy content like, for example, HY-80 and HY-100, are established materials for severe applications like pressure vessels and high performance pipes, submarines, civil construction, etc. However, their alloy designs are totally unsuitable regarding weldability, as they require special electrodes, pre-heating and highly skilled workmanship, factors that increase significantly the cost of structure fabrication. Thus the improvement of weldability of such materials is a constant solicitation from the fabricators of steel structures, as this improves their competitivity. But, as a matter of fact, it is the competitivity of steel as a material that is also increased.

Two new designs of microalloyed steels were proposed some years ago as alternatives to the HY-80 and HY-100 alloys, with similar mechanical strength level but better weldability, thanks to the minimization of their $\mathrm{C}$ content. They are the ASTM A710/HSLA-80 and ULCB-ultra low car-

\footnotetext{
* Corresponding author.

E-mail addresses: agorni@iron.com.br (A.A. Gorni), pmei@fem.unicamp.br (P.R. Mei).
}

bon bainite steels. Their better weldability allows a decrease of up to $50 \%$ in the total fabrication costs of components and structures [1]. Due to their low $\mathrm{C}$ content, such alloys must have strengthening mechanisms relatively independent from this element. In the case of the HSLA-80 steel, copper precipitation that occurs during a supplementary aging treatment represents a significant contribution to mechanical strength, while in the ULCB steel this role is played by the bainitic microstructure and solid solution hardening from alloy elements [2-7]. Although the presence of microalloy elements in the ULCB steel also promotes some hardening through precipitation in ferrite, this material normally is not submitted to aging treatments during its industrial processing.

Another advantage that arises from the use of such steels is the suppression of the quench and tempering treatment that normally is needed by the HY-80/HY-100 steels. It is true that the HSLA- 80 steels require aging treatment after hot rolling, but this has some favorable aspects during the forming process. The plate can be formed in the as-rolled condition, when its yield strength still is relatively low; the aging treatment can be applied subsequently to the component, after the welding and finishing steps, acting simultaneously as a stress relief treatment [2]. 
The HSLA-80 steel has, besides $\mathrm{Cu}$, significant contents of another alloy elements. Ni is added mainly to avoid problems associated to hot shortness normally present in $\mathrm{Cu}$ steels. For their turn, the role played by $\mathrm{Cr}$ and $\mathrm{Mo}$ is to retard $\mathrm{Cu}$ precipitation during the cooling after hot rolling, making easier its industrial processing. $\mathrm{Nb}$ is also added to this material, in order to take advantage of its classical grain refining effect during austenitizing and controlled rolling [1-3].

In the case of the HSLA-80 family a significant fraction of mechanical strength arise from the presence of $\mathrm{Cu}$. This element and $\mathrm{Fe}$ have similar values of atomic diameter and do not form intermetallic compounds between them. The maximum solubility of $\mathrm{Cu}$ in $\mathrm{Fe}$ is $2.4 \%$ at $840^{\circ} \mathrm{C}$ [8]. The aging treatment promotes precipitation of $\varepsilon-\mathrm{Cu}$ in the form of particles with diameter between 2 and $45 \mathrm{~nm}$. These particles are located in dislocations formed inside ferrite grains, as well its grain boundaries and sub-boundaries [2]. The electronic diffraction patterns showed that the $\varepsilon-\mathrm{Cu}$ precipitated is mainly constituted of $\mathrm{Cu}$, had a lattice parameter slightly greater than pure $\mathrm{Cu}$ and a maximum Fe content of 4\% [9]. In commercial steels these precipitates are covered by a $\mathrm{Mn}$ or Ni segregation [10].

The classical chemical composition of ULCB steels includes several alloying elements. B is essential to get a fully bainitic microstructure in such steels with an extra-low $\mathrm{C}$ content. Its association with $\mathrm{Nb}$ creates a synergistic effect that increases significantly austenite hardenability; besides that, $\mathrm{Nb}$ also promotes grain size refining in association with Ti. This latter element must also combine with all free $\mathrm{N}$ present in the steel, avoiding the combination of this element with $\mathrm{B}$, thus preserving the vital effect of this latter element. Also $\mathrm{Mn}, \mathrm{Ni}, \mathrm{Cu}$ and $\mathrm{Cr}$ can be added to the alloy, according to the aimed mechanical strength level and plate thickness [4-6,11-13].

The ULCB steels are also susceptible to aging when submitted to temperatures around 400 and $700^{\circ} \mathrm{C}$, since they have enough amounts of $\mathrm{Nb}$, $\mathrm{Ti}$ and $\mathrm{V}$ to promote secondary hardening. Tempering temperatures up to $400{ }^{\circ} \mathrm{C}$ lead to a moderate increase in mechanical strength without affecting significantly toughness. This reflects the release of residual stresses that were produced by phase transformations. For its turn, a tempering between 400 and $550{ }^{\circ} \mathrm{C}$ produces some decrease in mechanical strength, but this behavior is reverted if this temperature is increased to the $550-650^{\circ} \mathrm{C}$ range. The increase observed in strength is remarkable, but it is accompanied by a toughness decrease. The aging response is more intense for alloys that contain Ti instead of $\mathrm{V}[8,9]$.
The objective of this work is to characterize the CCT diagrams (transformation under continuous cooling) relative to the austenite of HSLA-80 and ULCB steels, as well as verify its behavior during aging under temperatures between 500 and $700{ }^{\circ} \mathrm{C}$.

\section{Materials and experimental procedure}

The alloys used in this work were produced in a vacuum induction furnace. One $100 \mathrm{~mm} \times 130 \mathrm{~mm} \times 850 \mathrm{~mm}, 85 \mathrm{~kg}$ ingot was produced for each studied alloy, that is, HSLA-80 and ULCB steels. Their chemical analysis can be seen in Table 1. These ingots were hot rolled into rectangular bars with $50 \mathrm{~mm} \times 42 \mathrm{~mm}$ cross-section in order to break and homogenize the as cast structure. Specimens for the hot rolling tests were machined from these bars. These specimens were reheated to $1200^{\circ} \mathrm{C}$ and hot rolled down to $7.5 \mathrm{~mm}$ thickness; the finishing temperature was $750^{\circ} \mathrm{C}$. Finally, these hot rolled samples were machined in order to get the samples used for the determination of CCT (continuous cooling transformation) diagrams and in the aging tests.

The CCT diagrams of both alloys were determined in order to characterize the evolution of austenite transformation during continuous cooling. A Formastor dilatometer was used; the samples were heated to $930^{\circ} \mathrm{C}$ during $20 \mathrm{~min}$; after this process both alloys showed an ASTM 9.5 austenitic grain size. Following this heating step the samples were cooled down with the following rates: 44, 30, 20, 10, 0.3, $2.67,1.33,0.5$ and $0.25^{\circ} \mathrm{C} / \mathrm{s}$. Cooling rates of $3{ }^{\circ} \mathrm{C} / \mathrm{s}$ or lower were attained using the automatic temperature control; cooling rates higher than that required the use of argon jets. The analysis of the volumetric variation of the samples during cooling and the final microstructures yielded data for drawing the CCT diagrams. The Vickers hardness of the samples were also measured using a $10 \mathrm{~kg}$ load.

The aging treatments were carried out using samples of both alloys with dimensions $10 \mathrm{~mm} \times 15 \mathrm{~mm} \times 7 \mathrm{~mm}$. They were aged at 500,600 and $700^{\circ} \mathrm{C}$ during $5,15,30,60$ and $120 \mathrm{~min}$. As the experimental design included very short aging treatments ( 5 and $15 \mathrm{~min}$ ), they had to be carried out using furnaces with high heating rate, minimizing the thermal inertia of the samples. For this reason these aging treatments were done in a liquid tin bath heated in a electric resistance furnace. The bath temperature was controlled using a $1.5 \mathrm{~mm}$ diameter chromel-alumel thermocouple protected with a stainless steel sheath immersed in the metallic bath. The cooling of the samples was done in still air. The chemical analysis of the sample surfaces aged in the most critical

Table 1

Chemical analysis of the studied heats

\begin{tabular}{llllllllllllllll}
\hline Steel & $\mathrm{C}$ & $\mathrm{Mn}$ & $\mathrm{Si}$ & $\mathrm{P}$ & $\mathrm{S}$ & $\mathrm{Al}_{\text {sol }}$ & $\mathrm{Ni}$ & $\mathrm{Cr}$ & $\mathrm{Cu}$ & $\mathrm{Mo}$ & $\mathrm{Nb}$ & $\mathrm{Ti}$ & $\mathrm{B}$ & $\mathrm{N}$ & \\
\hline HSLA-80 & 0.044 & 0.65 & 0.32 & 0.005 & 0.011 & 0.013 & 0.87 & 0.77 & 1.12 & 0.23 & 0.077 & - & - & 0.0030 \\
ULCB & 0.033 & 1.93 & 0.29 & 0.007 & 0.011 & 0.006 & 0.39 & - & - & 0.35 & 0.062 & 0.029 & 0.0016 & 0.0030 \\
\hline
\end{tabular}


situation $\left(120 \mathrm{~min}\right.$ under $\left.700^{\circ} \mathrm{C}\right)$, that was carried out using a electronic probe micro-analyzer, showed that no tin diffusion to the core of the samples was observed.

The hardening effect due to the aging treatment was determined through the measuring of the Vickers hardness of the samples; a test load of $5 \mathrm{~kg}$ was used. The surface of the samples were ground and polished before the tests. Ten values of hardness along the diagonal of the wider face of the sample were determined for each specimen and then a mean value was calculated. This procedure aims to minimize the influence of some eventual segregation and/or orientation present in the material.

\section{Results and discussion}

The CCT diagrams determined for the HSLA- 80 and ULCB steels are showed, respectively, in Figs. 1 and 2. The first figure shows that the HSLA- 80 is basically a bainitic steel, as it detected a very low fraction $(5 \%)$ of ferrite when the samples were cooled at $0.5^{\circ} \mathrm{C} / \mathrm{s}$ or lower cooling rates. The same fact was verified for the ULCB steel, which hardenability is even greater, as a ferritic field did not even appeared in Fig. 2. It must be noted that, in this case, the synergistic effect between $\mathrm{Nb}$ and $\mathrm{B}$ and the presence of Mo had an essential role in this result.

The low concentration of $\mathrm{C}$ in these alloys, particularly in the case of the ULCB steel, decrease or suppress the cementite formation between platelets in the bainitic ferrite matrix. Instead of cementite there is the formation of the so-called MA constituent, that is, a mixture of martensite plus retained austenite. As a matter of fact, the classification of the microstructure of the ULCB steels as seen in optical microscopy is very difficult, due to the acicular character of this constituent and the lack of resolution of this analysis method [13].

Fig. 3 shows the hardness evolution observed in the samples of HSLA-80 and ULCB in function of the applied cooling rate. Both alloys showed a good logarithmic correlation between hardness and cooling rate, with an correlation coefficient $r^{2}$ about 0.9. It can be clearly seen that the hardness of both alloys was virtually identical for low cooling rates, from 0.25 to $0.30^{\circ} \mathrm{C} / \mathrm{s}$. However, for greater values, hardness of the HSLA-80 steel increased slightly more than ULCB steel. Apparently this result can be attributed to the slightly higher $\mathrm{C}$ content and the presence of $\mathrm{Cu}$ in the HSLA- 80 alloy.

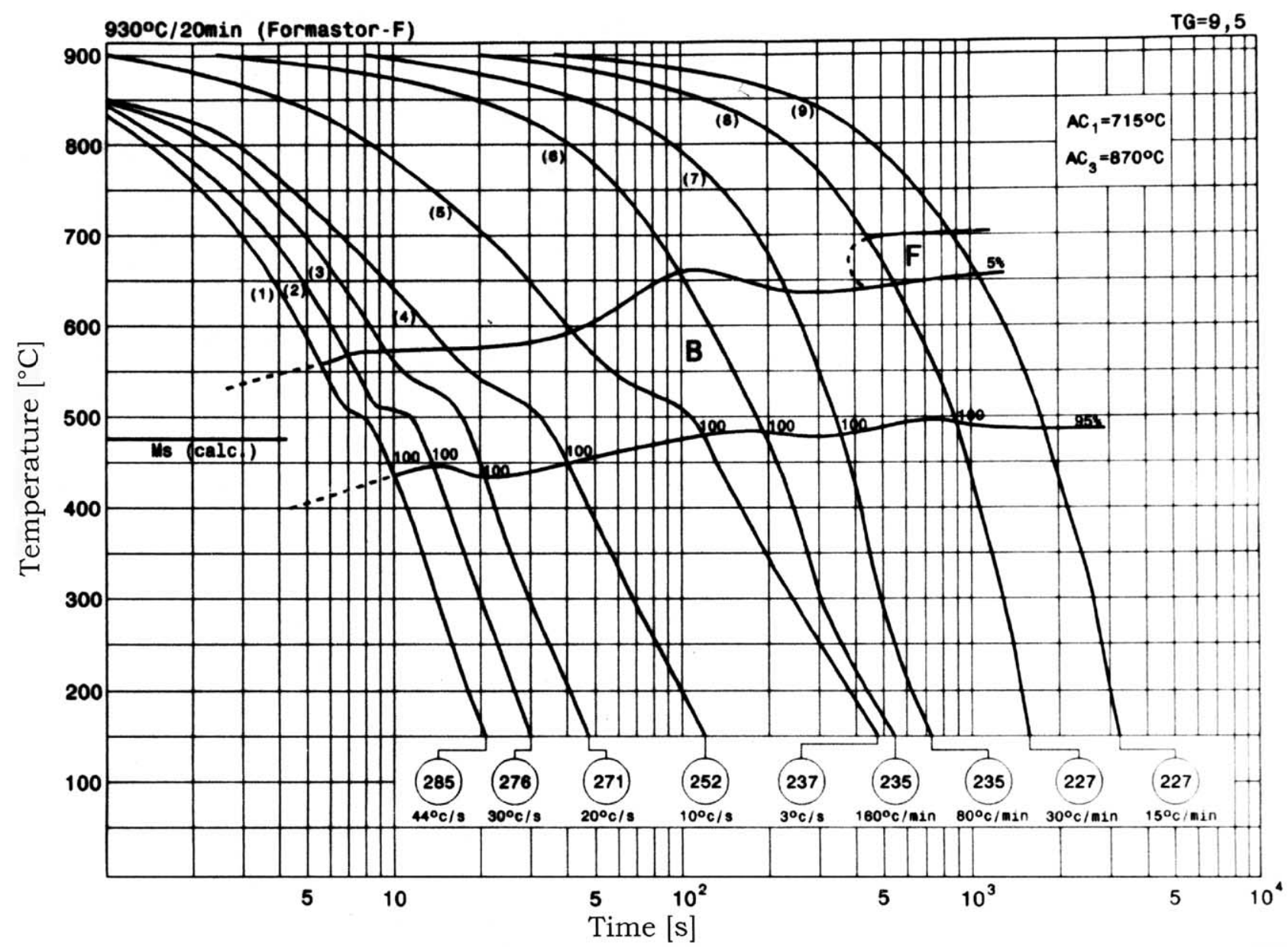

Fig. 1. Continuous cooling transformation diagram (CCT) determined for the HSLA-80 steel studied in this work. 


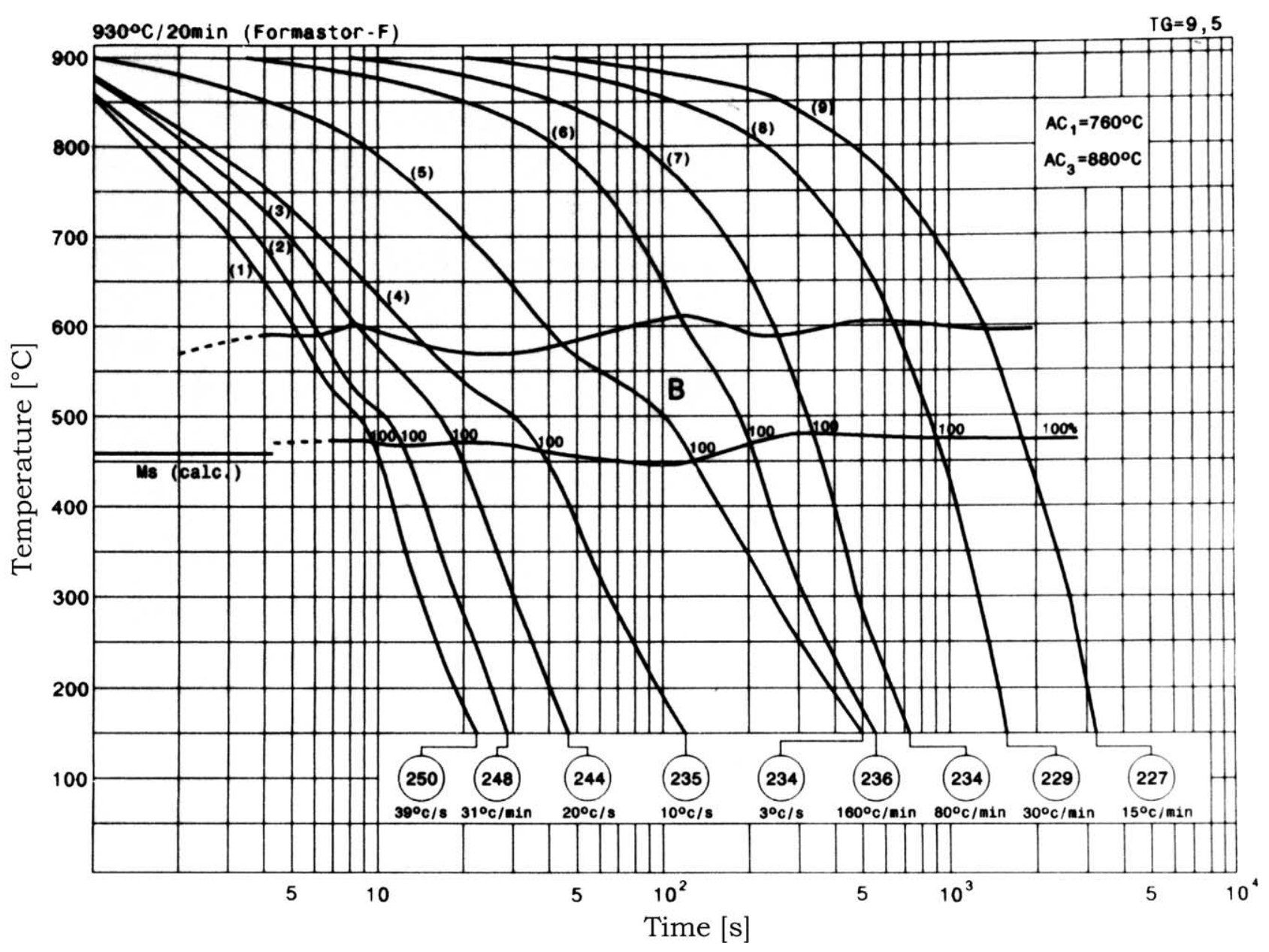

Fig. 2. Continuous cooling transformation diagram (CCT) determined for the ULCB steel studied in this work.

The use of the results got in these diagrams for the definition of process parameters for hot rolling must be done with care. It must be remembered that, as the samples used for the determination of these CCT diagrams were reheated to $930^{\circ} \mathrm{C}$, their soluble $\mathrm{Nb}$ content certainly was very low. The calculation of the solubilized contents of microalloying elements using thermodynamical models $[14,15]$ pointed that, under this temperature, the soluble $\mathrm{Nb}$ amount in the ULCB steel was about $0.016 \%$, only $29 \%$ from the total available

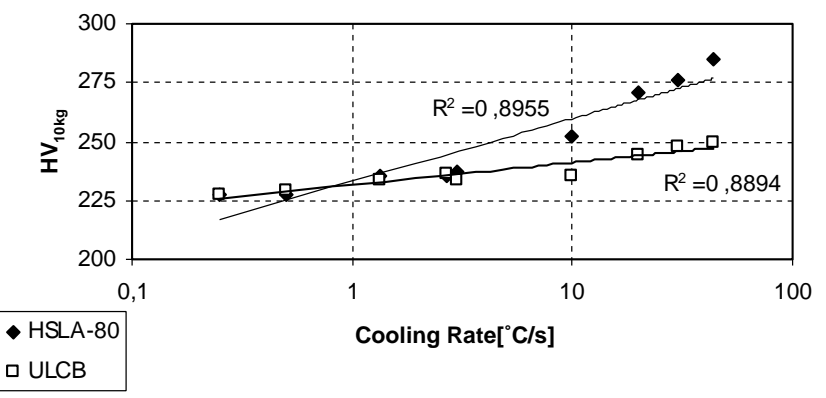

Fig. 3. Hardness evolution in function of cooling rate observed for the HSLA- 80 and ULCB steel samples used for the determination of the CCT diagrams. in the nominal composition of the alloy. This can be an additional cause for the lower hardness of the ULCB steel in comparison with the HSLA-80 steel, as the synergistic effect between $\mathrm{Nb}$ and $\mathrm{B}$ would be greatly affected by this low $\mathrm{Nb}$ content. It must be remembered that reheating temperatures used during industrial hot rolling practice are about $1200{ }^{\circ} \mathrm{C}$ or over; this assures a complete $\mathrm{Nb}$ solubilization.

Besides that, the Formastor dilatometer used in this work was not capable to apply hot forming to the samples before cooling. For this reason the effects of hot forming over austenite transformation were not reflected in the CCT diagrams determined in this work. Generally hot forming leads to an acceleration of austenite transformation [16].

The hardness evolution along aging treatment time for the alloys studied in this work, for each temperature used (500, 600 and $700^{\circ} \mathrm{C}$ ) can be seen in Fig. 4. It shows that, in the case of HSLA-80, the aging treatment at $500{ }^{\circ} \mathrm{C}$ promoted a very slight hardening. This sample, with a starting hardness of $244 \mathrm{HV}$, showed a fast increase in this parameter up to $30 \mathrm{~min}$ of treatment, reaching a value of $251 \mathrm{HV}$. The hardness values kept practically constant for longer treatment times up to $2 \mathrm{~h}$. For its turn, the aging treatment at $600{ }^{\circ} \mathrm{C}$ lead to a fast hardness increase, reaching a max- 
HSLA-80

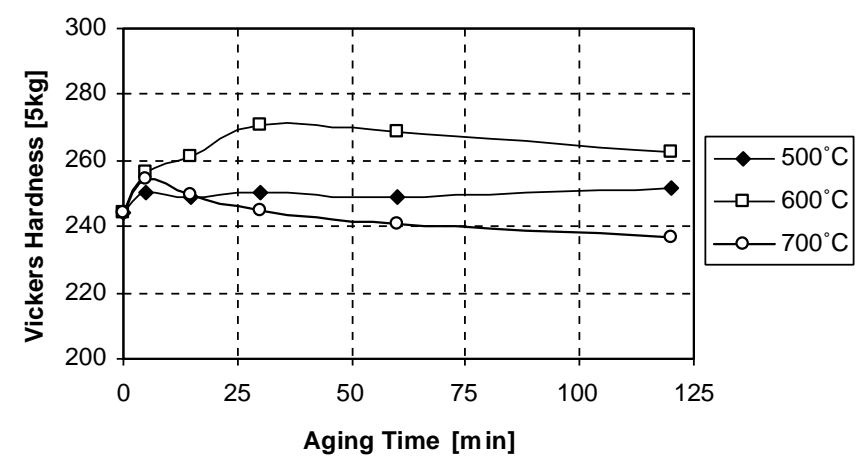

ULCB

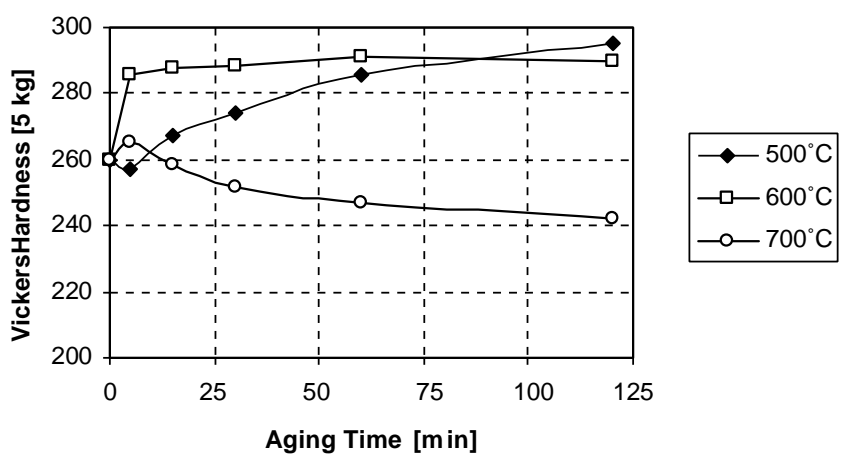

Fig. 4. Hardness evolution along aging time for the alloys studied in this work. The aging treatments were carried out under temperatures of 500 , 600 and $700^{\circ} \mathrm{C}$.

imum value after $30 \mathrm{~min}$ of treatment: $271 \mathrm{HV}$. From this point on hardness decreased slowly, reaching $263 \mathrm{HV}$ after $2 \mathrm{~h}$ of treatment. Finally, the aging at $700{ }^{\circ} \mathrm{C}$ lead initially to a small hardness increase, which reached a maximum value after $5 \mathrm{~min}$ of treatment, that is, $254 \mathrm{HV}$. From this point on hardness progressively decreased. At the end of the aging treatment the sample showed a hardness even lower than observed in the as-rolled condition: $237 \mathrm{HV}$.

The results show that the $500{ }^{\circ} \mathrm{C}$ aging is not enough to yield significative precipitation hardening, most probably due to the fact that this temperature is too low to promote a fast diffusion of the copper atoms for the formation of the hardening clusters. For the other side, $700{ }^{\circ} \mathrm{C}$ is too high a temperature: the precipitation hardening was replaced for treatment times above 5 min by a simultaneous tempering of the bainitic matrix and overaging. The temperature of $600^{\circ} \mathrm{C}$ was the best balance for the aging treatment, promoting a fast increase in the hardness values up to its maximum value, $271 \mathrm{HV}$, after $30 \mathrm{~min}$ of treatment. Longer times lead to overaging, as the sample showed a hardness of $263 \mathrm{HV}$ after $2 \mathrm{~h}$ of treatment.

Fig. 4 also shows that the hardness curve along aging time for the HSLA-80 steel showed only one peak, independent of the aging temperature used. This fact indicates that both precipitating phases, the $\mathrm{Cu}$-rich $\varepsilon$ and $\mathrm{Nb}$ carbonitride, are precipitating at the same temperature range. This fact was previously reported in the literature [17].

The hardness evolution of the ULCB steel during the aging treatments was faster than observed for the HSLA-80 steel, probably due to the different precipitates involved in the process. In the ULCB steel only niobium carbonitride precipitates. The aging of this alloy at $500{ }^{\circ} \mathrm{C}$ promoted a continuous hardness increase, from the starting value of 260 up to $295 \mathrm{HV}$ after a $2 \mathrm{~h}$ treatment. The increase of the temperature of the aging treatment to $600^{\circ} \mathrm{C}$ accelerated significantly the hardness response of the material, which increased from 260 to $286 \mathrm{HV}$ after only $5 \mathrm{~min}$ of treatment. From this point on hardness increased lightly, reaching a $291 \mathrm{HV}$ value after $1 \mathrm{~h}$ of aging. After this point hardness stabilized; at $2 \mathrm{~h}$ of treatment the sample showed almost the same value: $290 \mathrm{HV}$. For its turn, the behavior of the ULCB samples during aging under maximum temperature $\left(700^{\circ} \mathrm{C}\right)$ was similar to that observed for the HSLA-80 steel: a slight hardness increase after 5 min of treatment, from 260 to $265 \mathrm{HV}$, that was followed by a decrease for longer times: after $2 \mathrm{~h}$ of aging the hardness fell to only $243 \mathrm{HV}$, a value lower than the observed in the as-rolled sample. In this latter case apparently occurred the same mechanism observed in the HSLA-80 samples aged at $700{ }^{\circ} \mathrm{C}$ for $2 \mathrm{~h}$, that is, precipitation hardening was counterbalanced by tempering of the bainitic matrix and by precipitate overaging.

It is interesting to note that the hardness of ULCB steel was slightly higher than HSLA-80 in the as-rolled state: $260 \mathrm{HV}$ versus $244 \mathrm{HV}$, respectively. This hardness difference increases after $1 \mathrm{~h}$-aging treatment at $600^{\circ} \mathrm{C}: 291 \mathrm{HV}$ versus $268 \mathrm{HV}$, respectively. This behavior is opposite to what was observed during the determination of the CCT diagrams, where the hardness of the HSLA-80 samples were greater than the measured for the ULCB samples. This result can be explained by the fact that the samples submitted to the aging treatments were reheated to $1200^{\circ} \mathrm{C}$ before hot rolling, which promoted a major solubilization of the microalloying elements of both steels, specially niobium. Under these conditions the synergistic effect between this element and boron can be fully used to increase austenite hardenability of the ULCB steel [8,9].

\section{Conclusions}

This work about austenite transformation and aging of steels hardened by precipitation (HSLA-80) and with extra-low C-bainitic structure (ULCB) led to the following conclusions.

The CCT diagrams determined for these steels showed that both alloys formed a bainitic microstructure over a wide range of cooling rates, because their alloy content is relatively high. 
The HSLA-80 samples used for the determination of the CCT diagram were slightly harder than their counterparts of ULCB steel. This result can be attributed to the slightly higher $\mathrm{C}$ content of the first alloy and the low austenitizing temperature used, which contributed to an incomplete solubilization of microalloying elements in both steels.

Both alloys showed a significant hardness increase when submitted to aging treatments at $600^{\circ} \mathrm{C}$. This can be attributed to precipitation hardening in the bainitic matrix. In the case of the HSLA-80 steels the precipitates are supposed to be $\mathrm{Cu}$ plus $\mathrm{Nb}$ carbonitride, while in the ULCB steel only the latter constituent would be present.

The speed of aging is clearly dependent on the temperature used in this treatment. At $500^{\circ} \mathrm{C}$ this speed was minimal. At intermediate temperature, $600{ }^{\circ} \mathrm{C}$, there was an optimized balance between precipitation speed and maximum hardening. At $700{ }^{\circ} \mathrm{C}$ carbonitride precipitation apparently is too fast, promoting overaging. This implies in loss of precipitation hardening that, associated with simultaneous tempering of the bainitic matrix, led to a significant softening in both steels.

The precipitation hardening promoted by the aging treatment was faster for the ULCB steel, where only niobium carbonitride could precipitate during this step.

\section{Acknowledgements}

The authors would like to acknowledge the assistance of Rajindra Clement Ratnapuli during the determination of the CCT diagrams in the Research Center of USIMINAS and of Celso Gomes Cavalcanti during the aging treatments.

\section{References}

[1] T.W. Montemarano, et al., High strength low alloy steels in naval construction, J. Ship Prod. 2 (1986) 145-162.

[2] A.D. Wilson, et al., Properties and microstructures of copper precipitation aged plate steels, in: Proceedings of the Conference, Microalloying'88, Chicago, 1988, pp. 259-275.
[3] R.H. Phillips, et al., High strength plate steels for defence applications, in: Proceedings of the Conference, Microalloying' 88 , Chicago, 1988, pp. 235-247.

[4] C.I. Garcia, A.J. De ardo, Structure and properties of ULCB plate steels for heavy section applications, in: Proceedings of the Conference, Microalloying '88, Chicago, 1988, pp. 291-299.

[5] E.G. Hamburg, et al., Development of an Intermediate Composition for Navy HSLA-80/HSLA-100 Steels, Lukens Steel Company, Coatesville, 1988.

[6] C.I. Garcia, et al., Ultra-low carbon bainitic plate steels: processing, microstructure and properties, Iron Steelmaker 18 (1991) $97-$ 106.

[7] H. Nakasuji, et al., Development of controlled rolled ultra low carbon bainitic steel for large diameter linepipe, in: R.Q. Barr (Ed.), Proceedings of the Conference on Alloys for the Eighties, Ann Arbor, 1981, pp. 213-224.

[8] E. Hornbogen, et al., A metalographic study of precipitation of copper from alpha iron, Trans. Metall. Soc. AIME 218 (1960) 1064 1070.

[9] H.A. Wriedt, et al., The solubility of copper in ferrite, Trans. Metall. Soc. AIME 218 (1960) 30-36.

[10] K. Osamura, et al., SANS study of phase decomposition of $\mathrm{Fe}-\mathrm{Cu}$ alloy with Ni and Mn addition, ISIJ Int. 34 (1994) 346-354.

[11] A. Massip, et al., Grobblech und Warmband aus bainitischen Stählen mit sehr niedrigem Kohlenstoffgehalt, Stahl und Eisen 98 (1978) 989-996.

[12] S.C. Wang, et al., Effects of chemical composition, rolling and cooling conditions on the amount of martensite/austenite (M/A) constituent formation in low carbon bainitic steels, Mater. Sci. Eng. A 154 (1992) 43-49.

[13] T. Araki, et al., Bainitic intermediate microstructures of very low-C steels, in: Proceedings of the International Conference on Processing, Microstructure and Properties of Microalloyed and Other Modern HSLA Steels, Pittsburgh, 1992, pp. 249-255.

[14] A.A. Gorni, Spreadsheet Applications in Materials Science, in: G. Filby (Ed.), Spreadsheets in Science and Engineering, Springer-Verlag, Heidelberg, 1998.

[15] H. Adrian, Thermodynamic model for precipitation of carbonitrides in high strength low alloy steels containing up to three microalloying elements with or without additions of aluminium, Mater. Sci. Technol. 8 (1992) 406-420.

[16] Y. Desalos, et al., Influence de l'écrouissage de l'austenite sur les conditions de transformation d'aciers peu ou moyenemment alliés, Les Mémoires et Études Scientifiques de la Revue de Metallurgie 76 (1979) 377-396.

[17] G.E. Hicho, et al., Effects of heat treatment on the mechanical properties and microstructures of four different heats of a precipitation hardening HSLA steel, J. Heat Treating 5 (1987) 7-19. 